\title{
Outubro Rosa e Ensino de Ciências na Educação do Campo
}

\author{
Pink October and Science Education: in Field Education
}

\author{
Edinalva Oliveira e-mail (edinaoli@yahoo.com.br) \\ Curso de Licenciatura em Educação do Campo - Ciências da Natureza Universidade Federal do \\ Paraná - Setor Litoral
}

Resumo: O estudo descreve encaminhamentos adotados numa experiência de Estágio Supervisionado (Curso de Licenciatura em Educação do Campo - Ciências da Natureza UFPR-Setor Litoral). O objetivo foi discutir o câncer considerando o ensino ciências, saúde e qualidade de vida. A prática desenvolvida no mês de outubro/2019, no Colégio Estadual Quilombola Diogo Ramos, Adrianópolis. Oito etapas foram vivenciadas: Pesquisa - livros didáticos e internet, buscando subsídios sobre câncer, anatomia e fisiologia dos sistemas do corpo humano; Elaboração do Roteiro - para estruturar a apresentação teatral, resgatando os conteúdos ligados as ciências, valorizando alfabetização cientifica, o letramento científico e aliando a ludicidade; Montagem do Cenário - usando papelão, papel Kraft, papel crepom e outros materiais; Composição dos Personagens - adaptando fantoches e vestimentas; Apoio Logístico - cartazes, preparo do ambiente e gravação de áudios, conforme o roteiro; Ensaio - definição dos atores, leitura inicial e treino; Apresentação - para a comunidade escolar; e Roda de Conversa - culminância e reflexão, elencando os principais conceitos, habilidades e competências. O desencadeamento do processo, revelou evidências da apropriação de conteúdos conceituais, procedimentais e atitudinais, numa dimensão de aprendizagem significativa para os licenciandos em Educação do Campo e para os estudantes quilombolas desta comunidade escolar.

Palavras-chave: Aprendizagem $C$ Significativa; Teatro científico; Formação de professores.

Abstract: The study describes guidelines adopted in a Supervised Internship experience (Degree Course in Field Education - Natural Sciences UFPR- Coastal Sector). The objective was to discuss Cancer considering the teaching of science, health and quality of life. The practice developed in October/2019, at Colégio Estadual Quilombola Diogo Ramos, Adrianópolis. Eight stages were experienced: Research - textbooks and internet, looking for subsidies on cancer, anatomy and physiology of the human body systems; Elaboration of the Script - aimed to structure a theatrical presentation, rescuing the contents related to science teaching, valuing scientific literacy and combining playfulness; Setting the Stage - using cardboard, Kraft paper, crepe paper and other materials; Character Composition - adapting puppets and clothes; Logistical Support posters, environment preparation and audio recording, according to the script; Rehearsal - definition of the actors, initial reading and training; Presentation - to the school community; and Conversation Wheel - culmination and reflection, listing the main concepts, skills and competences. The triggering of the process revealed evidence of the appropriation of conceptual, procedural and attitudinal contents, in a dimension of significant learning for undergraduates in Field Education and for quilombolas students in this school community. 
Keywords: Meaningful learning; Science theater; Teacher training.

\section{INTRODUÇÃO}

Desde o final do Século XX e ainda nestas duas primeiras décadas do Século XXI gradativamente se reconhece a relevância da educação científica para a formação cidadã. Nessa dimensão, se destaca que a aprendizagem das ciências, potencializa o desenvolvimento do espírito crítico, possibilita o enfrentamento dos problemas e a busca por soluções frente a problemáticas da nossa realidade (CACHAPUZ et al., 2005).

O curso de Licenciatura em Educação do Campo - Ciências da Natureza - Setor Litoral da UFPR (Lecampo) é parte da proposta político pedagógica, estruturada para alavancar o desenvolvimento social da região Litoral e do Vale do Ribeira paranaense. Deste modo, a formação dos educadores do campo, nesta licenciatura, reconhece e respeita suas particularidades, trabalhando com práticas cotidianas e maneiras diferenciadas de aprender a aprender, partindo de vivências e problematizações vinculadas a realidade de cada estudante do campo, das águas e das florestas (SILVA et al., 2019).

Nesse entendimento, o Estágio Supervisionado se desenvolve articulando a formação curricular nos territórios de origem dos licenciados, entre os Tempo Universidade (TU) e o Tempo Comunidade (TC). Numa construção, que se pauta nas diferentes áreas do conhecimento cientifico, social, cultural e docente, tencionando ainda um envolvimento dinâmico e contextualizado na educação básica do campo, permeado por princípios filosóficos e políticos que sustentam a docência emancipatória (PPC Lecampo, 2012)

Entre os campos de estágio insere-se o Colégio Estadual Quilombola Diogo Ramos, sediado na Comunidade Quilombola de João Surá, município de Adrianópolis, Estado do Paraná. Este, apresenta um Projeto Político Pedagógico com elementos para o fortalecimento da luta quilombola, conforme referenciais das Lei $\mathrm{n}^{\mathrm{o}} 4.887$ e Lei n¹0.639. Neste estabelecimento a educação básica atende desde as Séries Finais do Ensino Fundamental ao Ensino Médio, fundamentando seus contextos pedagógicos nas Diretrizes Curriculares da SEED (PARANÁ, 2006; 2010), aliando ainda os 
conhecimentos acadêmicos aos saberes tradicionais quilombolas (PPP COLÉGIO ESTADUAL QUILOMBOLA DIOGO RAMOS, 2016).

Com estas bases, o presente relato almeja socializar o desenvolvimento e compartilhar os pressupostos que ampararam uma experiência de Estágio Supervisionado. Esta foi vivenciada pela autora atuando como supervisora de estágio junto aos estudantes da Lecampo, no módulo Estágio Supervisionado II. A intencionalidade foi aplicar o teatro científico como estratégia de ensino aprendizagem, utilizando como temática o câncer. Desta forma, os conteúdos estruturantes das Ciências Naturais e os Temas Transversais Contemporâneos foram explorados numa perspectiva de aprendizagem significativa.

\section{BASES TEÓRICAS}

O mundo contemporâneo está imerso em produtos que resultam da construção do conhecimento científico, nos mais variados setores, desde espaços residenciais, industriais e escolares. Todavia, nas duas primeiras décadas deste século XXI a ciência ainda enfrenta o desafio de socializar o conhecimento para todos. Consequentemente, emerge a preocupação em mitigar a distância entre o atual desenvolvimento científico e tecnológico e o grau de desconhecimento da sociedade sobre a dinâmica do funcionamento das ciências. Desta forma, a divulgação científica, busca maneiras ou estratégias de comunicar a ciência, seja no espaço formal da educação (a sala de aula na escola) ou através de um processo educativo não-formal (CAZELLI; FRANCO, 2001; ABREU, 2001; SILVEIRA; ATAÍDE; FREIRE, 2009).

Nesse caminho, manifestações lúdicas, tais como teatro, música, charges e ainda os museus de ciências, constituem ferramentas diversificadas e dinâmicas, que promovem a divulgação dos conhecimentos nas ciências de forma acessível e numa dimensão de educação científica que se pretende ser mais significativa. Assim sendo, o elo entre ciências e artes se torna vez mais estreito e o estudante encontra prazer no aprendizado das ciências (MATOS, 2003; CALDAS, 2004; MASSARANI, 2004; REIS; GUERRA; BRAGA, 2005; ZANETIC, 2006; MASSARANI; ALMEIDA, 2006).

O Outubro Rosa compreende um programa especial de saúde pública, na amplitude da Atenção Básica do Sistema Único de Saúde. Neste se busca articular o saber profilático, o diagnóstico e o universo simbólico e cultural dos que convivem com 
o câncer como enfermidade. Essa doença emerge como resultado de um processo, no qual estão inseridos os sujeitos, o meio e todo o universo cultural, social e econômico, que interferem de forma expressiva nos aspectos comportamentais e nas inter-relações dos que convivem com esta realidade (COUTO et al., 2017).

O espaço escolar oferece aos estudantes diferentes experiências de aprendizagem, que possibilitam o acesso aos fundamentos científicos do conhecimento. As mais expressivas, são aquelas que atingem os domínios cognitivo, emocional, social e motor. Estas envolvem os aprendizes numa dinâmica de aprender que transcende os conteúdos classicamente apresentados na grade curricular. Dessa forma, o papel do mediador/professor/educador será encontrar estratégias que oportunizam os meios de provocar e despertar o interesse dos estudantes. Nessa construção, o emprego de abordagens teatrais imputa aos estudantes a necessidade de agir para aprender. Nesse roteiro o aprendiz se envolve, efetivamente no processo ensino aprendizagem, deixando de ser está, um ato mecânico. Em decorrência desta dinâmica, se garante a apropriação do conhecimento e da cultura, de modo significativo, flexível e com garantia da longevidade na apropriação dos conhecimentos em estudo, tornando o processo ensino aprendizagem significativo (AUSUBEL; NOVAK; HANESIAN, 1980; OLIVEIRA; STOLTZ, 2010).

\section{CAMINHOS METODOLÓGICOS}

A experiência de estágio foi desencadeada no TC da Turma Sepé Tiaraju com cinco estudantes (Danilo Gonçalves de Matos, Gislaine Neves Galvão Pereira, Micheli Lima Pereira, Orail Andrade de Matos e Oriel Andrade de Matos), em outubro de 2019. Partimos de um diálogo com a equipe pedagógica do colégio e as professoras das turmas de Ensino Fundamental, nas quais os estagiários desenvolvem sua prática pedagógica. Neste momento foi solicitado aos estagiários, o desenvolvimento de uma abordagem aplicando o Tema Gerador Outubro Rosa.

Desta forma, a justificativa para a abordagem foi gestada em dois contextos: 1) solicitação das professoras de sala de aula aos estagiários para desenvolverem uma oficina pedagógica com foco na anatomia e fisiologia dos sistemas do corpo humano e 2) implicações do câncer nos tecidos humanos, uma vez que a doença é comum na localidade e no mês de Outubro a escola busca promover ações de sensibilização. 
Diante deste desafio, conduzimos nossa orientação, associando os conteúdos estruturantes das ciências aos Temas Transversais Contemporâneos. Buscamos dar destaque para a Saúde e a Qualidade de Vida, numa perspectiva interdisciplinar. Para atingir nossos anseios, nos engajamos no desenvolvimento de um Teatro Científico. A opção pelo teatro se deve a crença no seu potencial para despertar o envolvimento dos estagiários, potencializar a apropriação dos saberes em estudo a ainda favorecer a criatividade dos mesmos. Desta forma, sistematizamos o processo ensino aprendizagem em oito etapas, cada uma das quais descritas a seguir:

Pesquisa - conduzimos nossa busca em livros didáticos e revistas científicas por meio da internet, com o intuito de obtermos subsídios sobre a anatomia e fisiologia dos sistemas do corpo humano, dos processos fisiológicos que se estabelecem no Câncer e em decorrência do mesmo. Cada estagiário selecionou uma parte do conteúdo e numa roda de conversa compartilhamos os conhecimentos em estudo, assim na troca de saberes todos ganham novos conhecimentos. Além disso, nessa etapa procuramos discutir sobre o uso do teatro científico, como abordagem metodológica para o ensino de ciências.

Elaboração do Roteiro - selecionamos como foco do teatro científico a anatomia e fisiologia dos sistemas digestório, circulatório, respiratório e reprodutor, considerando os principais tipos de câncer que afetam os tecidos dos órgãos de cada sistema. No intuito de valorizamos a alfabetização cientifica, o letramento científico e ainda aliamos a ludicidade, preparamos um roteiro composto em dois atos. Para ampliar o pertencimento, nosso texto foi estruturado como uma escola do campo e tendo como personagens: professora, estudantes e narrador. A essência do roteiro se apresentou como uma aula de ciências, na qual os estagiários se engajam como professor e estudante da escola do campo, numa vivência de articulação dos saberes em estudo.

Montagem do Cenário - reutilizamos papelão de caixas, papel Kraft, papel crepom e outros materiais para compor o cenário (local de apresentação) e outros elementos do roteiro, alguns destes são apresentados na Figura 1. Composição dos Personagens - sendo o espaço de apresentação um ambiente pequeno, optamos por usar fantoches, o que facilitou a dinâmica de participação dos estagiários, visto ser essa a primeira vez que se usou o teatro como estratégia. Dessa forma, fizemos algumas 
adaptações, conforme nosso roteiro e confeccionamos vestimentas para os personagens, produzimos cartazes para que pudessem ser aplicados no palco de apresentação.

Apoio Logístico - o ambiente de apresentação, os cartazes explicativos sobre o câncer em cada um dos sistemas inseridos no roteiro, sonoplastia para inserções na dinâmica do roteiro foram preparados conforme a necessidade durante a abordagem. Um dos estudantes ficou responsável utilizando o Youtube para selecionar e gravar os áudios de apoio. Assim, este estudante atuou como narrador e auxiliar dos colegas durante a apresentação.

Ensaio - o processo coletivo e reflexivo de desenvolvimento do roteiro, preparo do cenário e personagens trouxe várias expectativas para os estagiários. E nesta etapa cada um foi livre para escolher o seu personagem. Nossa necessidade de personagens foi além dos cinco estagiários, desta forma alguns licenciandos tiveram que atuar, ocupando mais de um papel, sem que houvesse sobrecarga para ninguém e os saberes em estudo fossem garantidos. Cada estagiário, leu o roteiro e ensaiamos, buscando dar luzes ao envolvimento da arte e das ciências de modo harmônico.

Apresentação - foi realizada no período vespertino para todos os estudantes do colégio, até mesmo aqueles cujas turmas não tinham estagiários. Essa decisão da equipe pedagógica de envolver as demais turmas surpreendeu os estagiários, ampliando o valor do desafio pedagógico. A essência do processo ensino aprendizagem, passou a considerar as abordagens de sala de aula como concebidas junto aos Temas Transversais Contemporâneos, tendo a saúde como foco principal. Nesse sentido, o contexto dos diálogos durante os conceitos abordados, buscaram favorecendo o desenvolvimento de atitudes e valores relativos aos conteúdos em estudo sobre anatomia, fisiologia e o estabelecimento do câncer nos tecidos do corpo humano.

Roda de Conversa - processo de culminância e reflexão realizado em três momentos. O primeiro imediatamente após a apresentação entre supervisora de estagio e estagiários. O segundo desencadeado no diálogo entre estagiários e os estudantes do Colégio Diogo Ramos, articulando questionamentos e verificando dúvidas. O terceiro no TU, dialogando com os demais colegas da turma Sepé Tiaraju e a supervisora de estágio, explorando dificuldades e as vantagens do uso do teatro científico, como estratégia de ensino. Nestes momentos, buscamos sempre valorizar os principais 
conceitos, as habilidades e competências vivenciados, as ansiedades e os pontos positivos da prática pedagógica.

\section{RESULTADOS E DISCUSSÃO}

Iniciamos nossa reflexão explorando a Sinopse do Roteiro: O texto outubro rosa apresenta no primeiro ato: $\mathrm{O}$ dia primeiro de outubro como uma manhã comum na rotina de nossa escola. Nesta data, a professora Jovita, entra na sala de aula com um laço de fita rosa preso ao seu jaleco, e dialoga com os estudantes do Oitavo Ano do Ensino Fundamental. Ela os questiona se sabem porque ela está usando o laço rosa? Após alguns palpites, bons e mal sucedidos a professora retoma a abordagem e explica que seu laço tem relação com o outubro rosa. Os estudantes intrigados buscam esclarecer melhor o significado deste emblema e sua relação com a aula de Ciências.

Com esta sensibilização para o conhecimento, a professora destaca que neste mês se dedicará uma parte dos conteúdos ao estudo do câncer, enquanto processo fisiopatológico dos sistemas que formam o corpo humano. Os estudantes interagem e apontam ter familiares ou conhecidos na comunidade que sofrem desta enfermidade e que aprender e entender essa doença tem importância em sua realidade. Com base neste argumento, a professora elenca quais seriam os principais tipos de câncer que ocorrem na região de Adrianópolis. Nesta fala, fica evidente as implicações desta doença no estudo da anatomia e a fisiologia humana. Na sequência a professora combina com os estudantes e faz um sorteio dos temas, apresentando um roteiro de estudo. No encaminhamento explicativo, ela articula algumas sugestões de como os estudantes deveriam pesquisar e elaborar um material (cartaz ou folder), estudar e trazer estes na próxima aula, para compartilhar com os colegas e a professora. Ela procura incentivar os estudos destacando sua ansiedade e deixa evidente querer ser surpreendida pelos resultados. Deste modo, termina o primeiro ato com cada estudante, tomando a condução e indo para sua casa preparar seus estudos.

Segundo ato: Após uma semana, novamente temos aula de Ciências e Jovita entra em sala com seu laço rosa. A professora faz a acolhida inicial, e a seguir procede a retomada dos conteúdos em estudo. Aborda na sua explicação o conceito de câncer e as diferenças fisiopatológicas entre células doentes e células sadias, usando um modelo didático. A seguir interage com os estudantes verificando, que todos trouxeram cartazes 
para a aula. No diálogo os estudantes contam que pesquisaram em livros e na internet sobre o tema que sortearam. Na sequência a professora conduz sua aula solicitando a participação e o envolvimento de cada estudante para compartilhar com os colegas o que pesquisou.

A estudante Bianca apresenta seu estudo considerando a pele como o maior órgão do corpo humano e o câncer de epitelial, ou de pele, como um problema grave de muitas consequências para a saúde e qualidade de vida. Ela resgata os fatores que colaboram para esta doença acometer uma pessoa e também aponta formas de prevenção, apontando a necessidade da proteção a exposição direta ao sol. O estudante Gabriel explica sobre o sistema reprodutor feminino e o câncer de mama e de colo de útero. Nessa explicação ele destaca a importância de todos tomarem a Vacina HPV, que ajuda na prevenção do câncer de colo de útero. Usando um cartaz, ele explica como se pode fazer o auto exame e os sinais de alerta em relação ao câncer de mamas.

O estudante Rafael traz sua abordagem sobre o sistema reprodutor masculino e o câncer de próstata, ressaltando a anatomia e fisiologia desta pequena glândula, de importante função na biologia do homem. Ele faz uma ressalva sobre a necessidade de consultas periódicas e as implicações desta doença na fertilidade, explora também os tabus que existem em relação ao exame. A estudante Elena explica sobre os componentes do sistema respiratório e apresenta em detalhes o câncer de pulmão usando um folder ela compara um pulmão sadio a um pulmão doente. De forma esclarecedora apresenta a relação deste câncer com o tabagismo, valorizando em sua explicação os males desta prática em todas as idades.

Durante as abordagens de cada estudante a professora faz apontamentos, indicando as conexões entre os conceitos e conteúdos em estudo e parabenizando aos seus estudantes pelo empenho, dedicação e preparo dos materiais. Ao final das exposições a professora incentiva e todos decidem por compor um mapa conceitual. Neste momento, se procura compor uma síntese do foi apropriado. Os estudantes afirmam que em casa irão conversar com a família e amigos sobre o emblema do outubro rosa. Nessa perspectiva, se procura garantir a relação entre o aprendizado de sala de aula e o cotidiano de cada estudante. Com o mapa conceitual pronto a aula é então encerrada tornando evidente os saberes compartilhados entre os envolvidos no 
processo. Assim, todos seguem para suas casas satisfeitos com o aprendizado desenvolvido.

Para Oliveira e Stoltz (2010), o uso do teatro de fantoches como estratégia de ensino aprendizagem, traz para o contexto pedagógico dimensões que configuram um universo peculiar de interação social e de manifestação da cultura. Esse desencadeamento, possibilita atingir vários objetivos, na intencionalidade dos "atores" que vivem a prática pedagógica. Além disso, a sociedade apresenta diferentes formas de linguagem, sendo as expressões artísticas uma destas. Indubitavelmente, o envolvimento nessa dinâmica oportuniza o desenvolvimento de capacidades cognitivas e afetivas em diferentes níveis. Essa percepção tornou-se clara nas expressões faciais e colocações pessoais de cada estagiário, durante a reflexão na roda de conversa. Cada um destacou os pontos positivos da vivencia. As pesquisas que realizaram e o compartilhamento de saberes auxiliaram no domínio dos conteúdos conceituais e procedimentais.

Nos diálogos do roteiro entre a professora e os estudantes a linguagem coloquial desta comunidade quilombola fez parte da dimensão cultural explorada. Mas também o conhecimento científico foi privilegiado de modo a estabelecer uma ponte entre o saber historicamente acumulado e o etnoconhecimento. Desta forma, se buscou garantir que os conceitos, definições e princípios da anatomia e fisiopatologia do câncer em cada tecido fosse reconhecido pela plateia. Nessa construção, corroboramos as proposições de Montenegro et al. (2005), os quais destacam o compromisso e a responsabilidade do teatro científico com a exatidão das informações, valorizando a divulgação da educação científica numa expressão de linguagem capaz de ser assimilada por todos os envolvidos.

Os conteúdos relacionados ao ensino de Ciências Naturais têm ampla relevância no entendimento da realidade. Através do seu aprendizado se permite que o estudante compreenda os processos e estruturas que possibilitam sua existência, enquanto componente da biodiversidade. Nessa visão, se torna fundamental que o educador oportunize o envolvimento do estudante em atividades vinculadas ao aprender ciências, fazendo ciências. Nestas situações, o estudante dialoga com os conceitos científicos e atribui-lhes significados (RODRIGUES; TEIXEIRA, 2018). Nessa rotina, conceber, produzir e apresentar um teatro científico, oferece estratégias de ensino dinâmicas e 
fundamentadas, que para os que pretendem ser educadores produzem memórias expressivas.

Araújo (2016) ressalta que nos processos de formação dos educadores do campo, os espaços não formais devem ser valorizados. Desta forma, o estágio na escola do campo, com abordagens construídas na comunidade possibilita ao estagiário uma inserção na realidade da escola do campo. Na observação, análise, interações coletivas e nos produtos elaborados nestas vivências, se amplia a apropriação do conhecimento do mundo real, seus desafios, conflitos e mazelas. Nessa trajetória, o estudante ressignifica sua prática pedagógica, em direção a sua responsabilidade social enquanto educador do campo; além obviamente de valorizar sua identidade e o seu pertencimento.

A ludicidade está enraizada no teatro científico, ela torna a prática pedagógica mais harmônica e agradável, permitindo ainda que o estudante explore sua criatividade, de luzes a sua imaginação e ao seu senso de responsabilidade para com a aprendizagem em construção. Desta forma, os conteúdos em estudo se articulam com a realidade sendo úteis na formação cidadã que se almeja constituir (CRISOSTIMO; KIEL, 2017)

A Figura 1 apresenta uma visão geral do espaço utilizado para o desenvolvimento da proposta de teatro científico, com destaque para os fantoches e outros materiais.

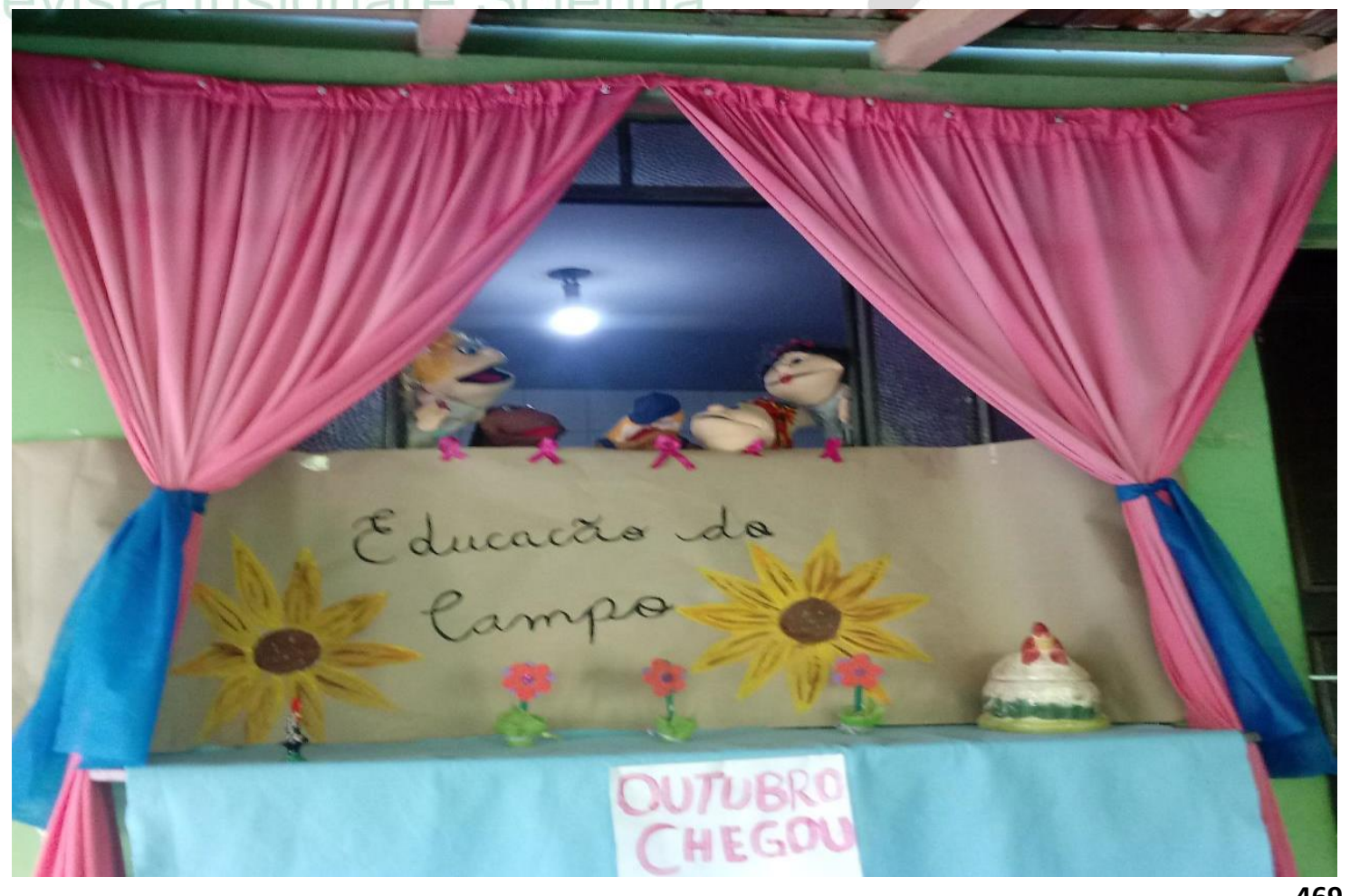

Recebido em: 10/09/2020 


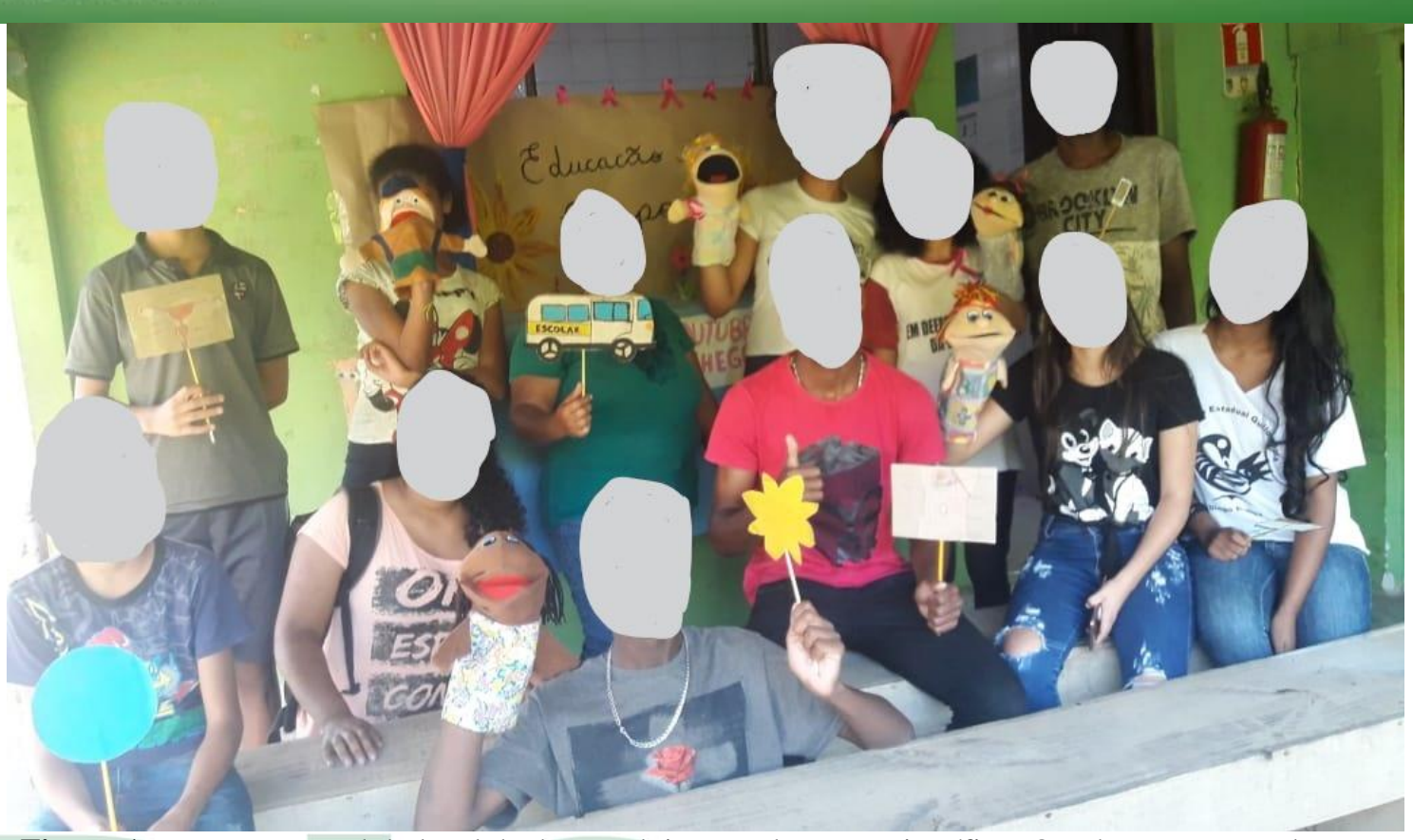

Figura 1 - Estrutura geral do local de desenvolvimento do teatro científico: Outubro Rosa na Educação do Campo e alguns dos envolvidos na proposta de ensino aprendizagem com recursos preparados no aprender fazendo ciências. Fonte: Autora, 2019.

Observando a figura reconhecemos desde elementos inseridos no cenário (fantoches, cartazes nas mãos dos estudantes), até outros materiais utilizados durante o desenvolvimento do roteiro e criados pelos estagiários. Durante todo o processo de concepção deste ambiente de aprendizagem, muitos saberes foram apropriados e a criatividade foi certamente uma grande aliada.

A dinâmica do estágio na Lecampo oscilando etapas de desenvolvimento entre os TU e o TC, com o supervisor estando junto ao estudante em seu território favorece a estruturação do planejamento das práticas docentes. Nos diálogos coletivos entre supervisor, professoras da escola do campo e estagiários, se buscam promover estratégias e experiências de estágio, que atendam às necessidades de todos. Essa perspectiva de construção didático pedagógica cria um processo contínuo de açãoreflexão-ação comprometido com as populações do campo e pautado nos princípios da Educação do Campo conforme destacado por Britto (2013). Além disso, Molina e Sá (2011), ressaltam que a alternância potencializa relações não hierárquicas na maneira como os conhecimentos científicos e conhecimentos produzidos nas vivências destes futuros educadores são articulados. 
Para os estudantes da Lecampo essa experiência de teatro científico, foi impar e a dinâmica em todas as etapas de sua realização. Ela trouxe a cada um deles situações de aprendizagem que certamente os acompanharão em sua atuação como educadores na escola do campo. Nesse entendimento, Rodrigues e Teixeira (2018) indicam que nas vivências de interpretações cênicas se passa a pensar o mundo como objeto a ser pensado e interpretado. Deste modo, na formação de educadores, essa estratégia oferece oportunidades do estudante envolver-se na prática e vivenciar experiências que permitem o diálogo com o conhecimento de referência através da construção e execução de encenações.

Destacamos ainda alguns pontos a favor da escolha do teatro cientifico e do uso de fantoches como relevantes para estagiários num curso de formação de educadores: a) a atividade lúdica estimula o estudante e atua como facilitadora da aprendizagem, potencializando o empenho para busca do conhecimento, b) as diferentes etapas inseridas na vivência (concepção do roteiro, desenvolvimento dos personagens, criação do cenários, preparo de músicas, cartazes) ampliam o desenvolvimento pessoal, social e cultural dos que a experimentam, c) o processo colabora para a promoção da saúde mental, facilitando a socialização, comunicação, expressão e apropriação do conhecimento, d) estimula a criatividade, expressão oral e corporal necessários na ação docente. Além disso, para os que assistem ao teatro científico o encantamento com as imagens e ações dos personagens, os conceitos e concepções explorados inserem o público num universo imaginário que possibilita de forma mais contundente a cognição dos conteúdos em abordagem.

Corroborando as reflexões anteriores Charlot (2013) aponta que o alcance do sucesso no teatro científico reside na imersão do estudante, neste caso representado pelos futuros educadores, na amplitude que a atividade oferece. Atuando como protagonistas do seu próprio aprender, ocorre uma mobilização e sensibilização, que culmina com a construção de destrezas que serão relevantes na atuação profissional futura.

Nessa dinâmica, a escola do/no campo se constitui num espaço de diálogo entre os conhecimentos pedagógicos e a realidade dos povos do campo, das águas e das florestas. Assim se garante uma formação integral do educador/educadora do campo, conduzida pela articulação de diferentes saberes: a complexidade dos processos de 
ensino aprendizagem, os conhecimentos específicos da área e o diálogo com os vínculos espacial, cultural e temporal destes sujeitos (CALDART, 2004).

Após o término da apresentação, os estagiários foram distribuídos nas diferentes turmas de estudantes do Ensino Fundamental e nestas desenvolveram ações de prática pedagógica, resgatando abordagens exploradas no teatro científico. Cada estagiário procurou ainda relacionar o teatro científico aos conteúdos em estudo no trimestre letivo. Para esta etapa, cada estagiário buscou preparar outros materiais pedagógicos (cartazes explicativos, textos informativos e estudo dirigido) e conduziu em sala de aula uma roda de conversa para esclarecer dúvidas e mediar a articulação dos conteúdos. Neste momento, os estudantes da educação básica, foram estimulados a refletir sobre o papel do teatro científico como meio de promover a aprendizagem das ciências.

O Estágio Supervisionado é um importante espaço de formação na área da licenciatura. Essa ferramenta oportuniza ao estudante uma inserção real nos fazeres profissionais, permitindo ao futuro educador refletir sobre as estratégias de abordagem dos conteúdos (PIMENTA; LIMA, 2004). Na mediação com o supervisor se exercita um processo de análise reflexiva, a partir do qual se potencializa o papel do conhecimento científico com a prática pedagógica. Nesse diálogo, ampliamos a autonomia do estagiário, que atuando como protagonista obtém os subsídios necessários para a apropriação do conhecimento. Desta forma, rompemos a visão fragmentada da aprendizagem, numa concepção que transcende a simples memorização (FREIRE, 2016).

Nessa amplitude de saberes Zabala (1998) esclarece a dimensão dos conteúdos vivenciados durante o processo ensino aprendizagem. $\mathrm{O}$ autor sistematiza três conteúdos principais: conteúdos conceituais relativos aos conceitos, princípios e dogmas academicamente elaborados. Conteúdos procedimentais articulados durante a construção das práticas vivenciadas em que o estudante se faz protagonista. E ainda os conteúdos atitudinais relacionados aos usos moral, valorativos e normativos, que as abordagens de sala de aula desencadeiam no estudante. Acreditamos, que a presente experiência cumpriu seu papel enquanto experiência de estágio, oportunizando a divulgação do conhecimento científico, promovendo a sensibilização para uma problemática local e articulando com a realidade da escola do campo. 


\section{CONSIDERAÇÕES FINAIS}

Todo espaço pedagógico apresenta claramente três atores: o educador, o estudante e o conteúdo em estudo. O desafio para o educador está em encontrar aliados para oportunizar uma aprendizagem significativa, flexível e lépida. Nesse caminho, encontramos no teatro científico, muitas possibilidades. Estas são expressivas enquanto potencializadoras do aprendizado de ciências.

A concepção, criação e desenvolvimento de um teatro científico, envolve de modo harmônico diferentes contextos. Os conceitos científicos são apresentados numa linguagem articulada com a realidade do público alvo. Nessa perspectiva, os estagiários imersos na vivência se perceberam como personagens principais e sua atuação garantiu a apropriação dos saberes da prática docente e ainda garantiu o aprendizado daqueles com quem compartilharam os conteúdos deste teatro científico.

A escola do/no campo, exige de sua comunidade a promoção e o desenvolvimento de situações práticas com nexos estreitos diante da realidade do campo. Além disso, desafiar estagiários a romper com o ensino tradicional e fragmentado cria um espaço, onde os mesmos podem fluir.

Nessa fluência de saberes, de forma contundente a ciência se expressa como ferramenta útil na formação de cidadãos cientificamente alfabetizados, capazes de pensar e agir racionalmente em busca de um mundo mais justo e articulado com contextos significativos.

\section{REFERÊNCIAS}

ABREU, Alice Rangel de Paiva. Estratégias de desenvolvimento científico e tecnológico e a difusão da ciência no Brasil. In: CRESTANA, Silvério; HAMBURGER, Ernest; SILVA Dilma M.; MASCARENHAS, Sérgio. (Org.). Educação para a ciência: curso para treinamento em centros e museus de ciência. São Paulo: Editora Livraria da Física, 2001. p. 23-28.

ARAÚJO, Gustavo Cunha de. Arte/educação no campo: algumas reflexões. In: SILVA, Cícero da; MIRANDA, Cássia Ferreira; AIRES, Helena Quirino Porto; OLIVEIRA, Ubiratan Francisco de (Org.). Educação do campo, artes e formação docente. Palmas/TO: EDUFT, 2016.

AUSUBEL, David Paul; NOVAK, Joseph Donald; HANESIAN, Helen. Psicologia educacional. Rio de Janeiro: Editora Interamericana, 1980. 
BRITTO, Néli Suzana. Prática Docente em Ciências da Natureza em Educação do Campo - Desafios, Diálogos, Reflexões e Ações Educativas. In: DUSO, Leandro; HOFFMANN, Marilisa Bialvo (Org.). Docência em Ciências e Biologia: propostas para um continuado reiniciar. Ijuí: Editora Unijuí, p. 107-134. 2013.

CACHAPUZ, Antonio; GIL-PEREZ, Daniel; PESSOA DE CARVALHO, Anna Maria; PRAIA, João; VILCHES, Amparo. (Org.). A Necessária renovação do ensino das ciências. São Paulo: Cortez, 2005.

CALDART, Roseli Salete. Elementos para construção do Projeto Político e Pedagógico da Educação do Campo. p. 10-31. In: MOLINA, Monica Castagna; JESUS, Sonia Meire Santos Azevedo de. (Org.) Contribuições para a construção de um projeto de Educação do Campo. Brasília, DF. Articulação Nacional por uma Educação do Campo, Coleção por uma Educação do Campo, n. 5. 2004.

CALDAS, Graça. O poder da divulgação científica na formação da opinião pública. In: SOUZA, Cidoval Morais de. (Org.). Comunicação, ciência e sociedade: diálogos de fronteira. Taubaté: Cabral Editora e Livraria Universitária, p. 65-79. 2004.

CHARLOT, Bernard. Da relação como o saber às práticas educativas. 1. ed. São Paulo: Cortez, 2013.

CAZELLI, Sibele; FRANCO, Creso; Alfabetismo Científico: novos desafios no contexto da globalização. Ensaio - Pesquisa em educação em Ciências, v. 3, n. 1, p. 1 18 , jun. 2001.

COLÉGIO ESTADUAL QUILOMBOLA DIOGO RAMOS. Projeto Político

Pedagógico: Colégio Estadual Quilombola Diogo Ramos. Quilombo João Surá, 2016.

COUTO, Vanessa Brito Miguel; SAMPAIO, Bernardo Pires; SANTOS Candice Messias Barbosa; ALMEIDA, Igor Santos de; SANTOS, Nicolle Guimarães Souza; SANTOS, Daniel Cézar; COELHO, Fátima Luísa Penha; MENEZES, Tallita Anny Matos de; CORREIA, Gustavo Soares; MEDEIROS, Scarlet Cardoso; GUZMAN, Julio Lenin Diaz. "Além da Mama": o Cenário do Outubro Rosa no aprendizado da formação médica. Revista Brasileira de Educação Médica, v. 41, n. 1: p. 30-37. 2017.

CRISOSTIMO, Ana Lúcia; KIEL, Cristiane Aparecida. O Lúdico e o ensino de ciências: saberes do cotidiano. Guarapuava: Ed. da Unicentro, 2017. 174 p.

FREIRE, Paulo. Pedagogia da autonomia: saberes necessários à prática educativa. 54 ${ }^{\mathrm{a}}$ ed. Rio de Janeiro: Paz e Terra, 2016.

MASSARANI, Luisa. A divulgação científica, o marketing científico e o papel do divulgador. In: SOUZA, Cidoval Morais de (Org.). Comunicação ciência e sociedade: diálogos de fronteira. Taubaté: Cabral Editora e Livraria Universitária, p. 81-94. 2004. 
MASSARANI, Luisa; ALMEIDA, Carla. Arte e Ciência no palco. (Entrevista com Carlos Palma). História, ciência e saúde - Manguinhos, v. 13 (suplemento), p. 233246, out. 2006.

MATOS, Cauê. (Org.). Ciência e Arte: imaginário e descoberta. São Paulo: Terceira margem, 2003.

MOLINA, Mônica Castagna; SÁ, Laís Moura. A Licenciatura em Educação do Campo da Universidade de Brasília: estratégias político pedagógicas na formação de educadores do campo. In: MOLINA, Mônica Castagna; SÁ, Laís Moura (Org.).

Licenciaturas em Educação do Campo: registros e reflexões a partir das experiências piloto. Belo Horizonte: Autêntica Editora, p. 35-61. 2011.

MONTENEGRO, Betânia; FREITAS, Ana Lúcia Ponte; MAGALHÃES, Pedro Jorge Caldas; SANTOS, Armênio Aguiar dos; VALE, Marcus Raimundo. O papel do teatro na divulgação científica: A experiência da Seara da Ciência. Ciência e Cultura, v. 57, n. 4, p: 31-32. 2005.

OLIVEIRA, Maria Eunice de; STOLTZ, Tânia. Teatro na escola: considerações a partir de Vygotsky. Educar, Curitiba, n. 36, p: 77-93, 2010.

PARANÁ. Secretaria de Estado da Educação. Diretrizes Curriculares da Educação do Campo. Paraná: 52p. 2006.

PARANÁ. Secretaria de Estado da Educação. Educação escolar quilombola: pilões, peneiras e conhecimento escolar / Secretaria de Estado da Educação. Superintendência da Educação. Curitiba: SEED. 101 p. - (Cadernos temáticos da diversidade). 2010.

PIANOWSKI, Fabiane. Educação do campo e o ensino de artes visuais: contexturas. Invisibilidades: Revista Ibero-Americana de Pesquisa em Educação, Cultura e Artes, n. 6, p. 70-77, 2014.

PIMENTA, Selma Garrido; LIMA, Maria Socorro Lucena. Estágio e docência: diferentes concepções. Revista Poíesis, v. 3, n. 3 e 4, p: 5-24. 2005/2006.

PORTO, Marcelo Duarte; SANTOS, Mirley Lucilene dos; FERREIRA, João Roberto Resende (Org.) Os desafios do ensino de ciências no século XXI e a formação de professores para a educação básica. Curitiba, PR: CRV, 2016. coedição: Anápolis, GO: UEG, 2016.

PPC-LECAMPO. Projeto Pedagógico De Curso Licenciatura Em Educação do Campo. Universidade Federal do Paraná: Setor Litoral. 2012. Disponível em: <http://www.litoral.ufpr.br>. Acesso em: 9/08/2020.

REIS, José Cláudio; GUERRA, Andreia; BRAGA, Marcos. Física e arte: A construção do mundo com tintas, palavras e equações. Ciência e Cultura, São Paulo, v. 57, n. 3, p. 29-32, 2005. 
RODRIGUES, Aleilson da Silva; TEIXEIRA, Ana Maria Freitas. Teatro científico e mobilização: aproximações a partir de um balanço bibliográfico e a teoria da relação com o saber. Ensino de Ciências e Tecnologia em Revista, v. 9, n. 3, p: 49-60. 2018.

SILVA, Valentim; ANDREOLI, Vanessa Marion; BOCCHI Gonçalves Michele; DAHMER, Gilson Walmor. Formação de professores em Educação do Campo: pedagogia do movimento emancipatório Revista de Educação, Ciência e Cultura, v. 24, n. 1, p. 53-70, 2019.

SILVEIRA, Alessandro Frederico da; ATAÍDE, Ana Raquel Pereira de; FREIRE, Morgana Lígia de Farias. Atividades lúdicas no ensino de ciências: uma adaptação metodológica através do teatro para comunicar a ciência a todos. Educar, n. 34, p. 251262, 2009.

ZABALA, Antoni. A prática educativa: como ensinar. Porto Alegre: ArtMed, 1998.

ZANETIC, João. Física e Arte: uma ponte entre duas culturas. Pro-posições, v. 17, n. 1, p. 39-58, 2006.

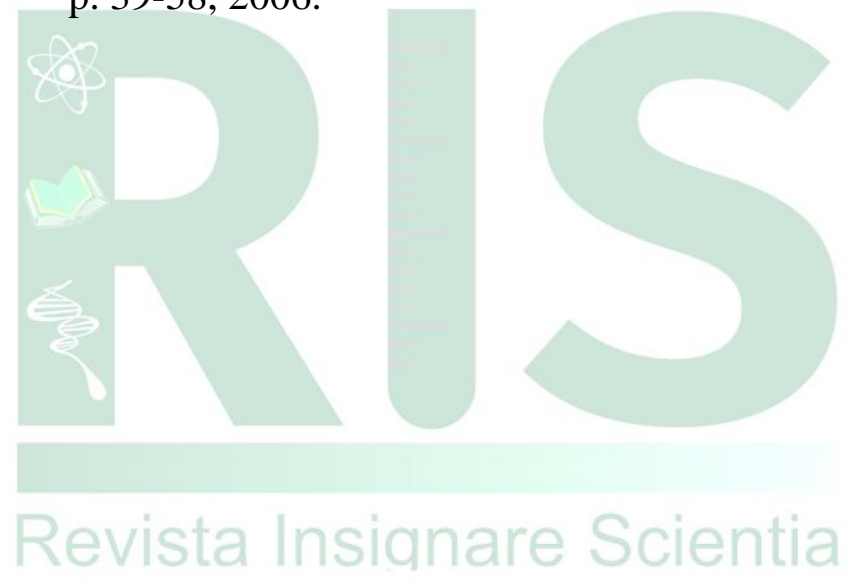

